\title{
Isolation of H8N4 avian influenza virus from wild birds in Shanghai, China
}

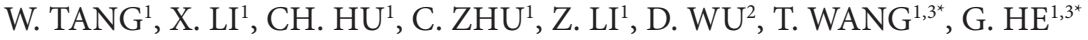 \\ ${ }^{1}$ School of Life Sciences, East China Normal University, Shanghai, P. R. China; ${ }^{2}$ Shanghai Wildlife Conservation and Management \\ Center, Shanghai, P. R. China; ${ }^{3}$ Institute of Eco-Chongming (IEC), East China Normal University, Shanghai, P. R. China
}

Received September 2018; accepted December 11, 2018

\begin{abstract}
Summary. - The H8 subtype viruses are rarely isolated from wild ducks. Shanghai is one of the important wintering or stopover sites on the East Asia-Australia Migration Flyway. An influenza virus, subtype H8N4, was firstly isolated from a common teal (Anas crecca) in Shanghai during 2017-2018 in this study. To clarify the genetic characteristics of the H8N4 virus, the whole genome sequences were analyzed. Phylogenetic analysis of the hemagglutinin and neuraminidase genes showed that they shared highest nucleotide identity (99.19\%-99.64\%) with the Japan duck-origin H8N4 virus collected in 2016 (A/duck/Aichi/231003/2016) and belonged to the Eurasian-like avian lineage. Six other genes of the H8N4 isolated virus were all highly similar to the corresponding genes of a wide range of AIV subtypes including H9N2, H5N7, H3N8, H1N2, H4N6 and H1N1. The results indicated that the H8N4 virus was a multiple reassortant virus. The study emphasized that the continuous surveillance of influenza virus in wild birds should be strengthened.
\end{abstract}

Keywords: avian influenza virus; H8N4; phylogenetic analysis; Shanghai

Avian influenza can cause worldwide outbreaks and even pandemics in humans and animals every year with considerable morbidity and mortality (Hill et al., 2012). Wild birds, as the natural reservoirs of avian influenza viruses (AIVs), contribute to the spread, variation, recombination and outbreak of AIVs in a wide geographic range along their flyways (Butt et al., 2005). More than 140 subtypes have been potentially generated through the combinations of different hemagglutinin (HA) and neuraminidase (NA) subtypes (Fouchier et al., 2005; Wu et al., 2014) and most subtypes can be detected in wild birds. Shanghai is one of the important habitats in the East Asian-Australian migratory bird migration route (Webster et al., 1992), providing a good habitat for a large number of wintering migratory birds. In the surveillance of AIVs in wild birds in Shanghai during 2017-2018, we isolated a strain of H8N4 AIV. To better understand the epidemiology of the H8N4 isolates in

${ }^{*}$ Corresponding authors. E-mails: thwang@bio.ecnu.edu.cn (T. Wang), gmhe@bio.ecnu.edu.cn (G. He); phone: +86-2162235786 .

Abbreviations: $\operatorname{AIV}(\mathrm{s})=$ avian influenza virus(es); $\mathrm{HA}=$ hemagglutinin; $\mathrm{NA}=$ neuraminidase wild birds, sequence and phylogenetic analysis of the virus were performed in this study.

From April 2017 to January 2018, oropharyngeal and cloacal swabs were sampled from apparently healthy wild birds in Chongming Dongtan ( $\left.31^{\circ} 91^{\prime} \mathrm{N}, 121^{\circ} 96^{\prime} \mathrm{E}\right)$ and Nanhui Dongtan $\left(30^{\circ} 90^{\prime} \mathrm{N}, 121^{\circ} 98^{\prime} \mathrm{E}\right)$ wetlands of Pudong, and Jiuduansha Natural Reservation Zone ( $\left.31^{\circ} 36^{\prime} \mathrm{N}, 121^{\circ} 74^{\prime} \mathrm{E}\right)$, Shanghai, China, with the permission and supervision of the Shanghai Wild Life Conservation and Management Office. All birds were released after sampling. The collected samples were placed in the eppendorf tubes with $2 \mathrm{ml}$ of viral transport media and stored at $-80^{\circ} \mathrm{C}$ for further molecular analysis. Viral RNAs were extracted from the swab samples on a Magmax-96 Express instrument (Applied Biosystems) using the MagMAX ${ }^{\mathrm{T}}$ Pathogen RNA/DNA Kit (Applied Biosystems, USA). RNAs were screened using a real-time reverse transcription PCR detection system on a 7500 RealTime PCR (Applied Biosystems, USA) with primers specific for the $\mathrm{M}$ gene (WHO, 2009). The positive viral RNAs were transcribed into cDNA using the Uni12 primer (5'-AGC AAA AGC AGG-3') and PrimScript ${ }^{\mathrm{Tm}}$ II 1st Strand cDNA Synthesis Kit (Takara, Japan). The eight segments of the subtypes were then amplified using the universal primers 


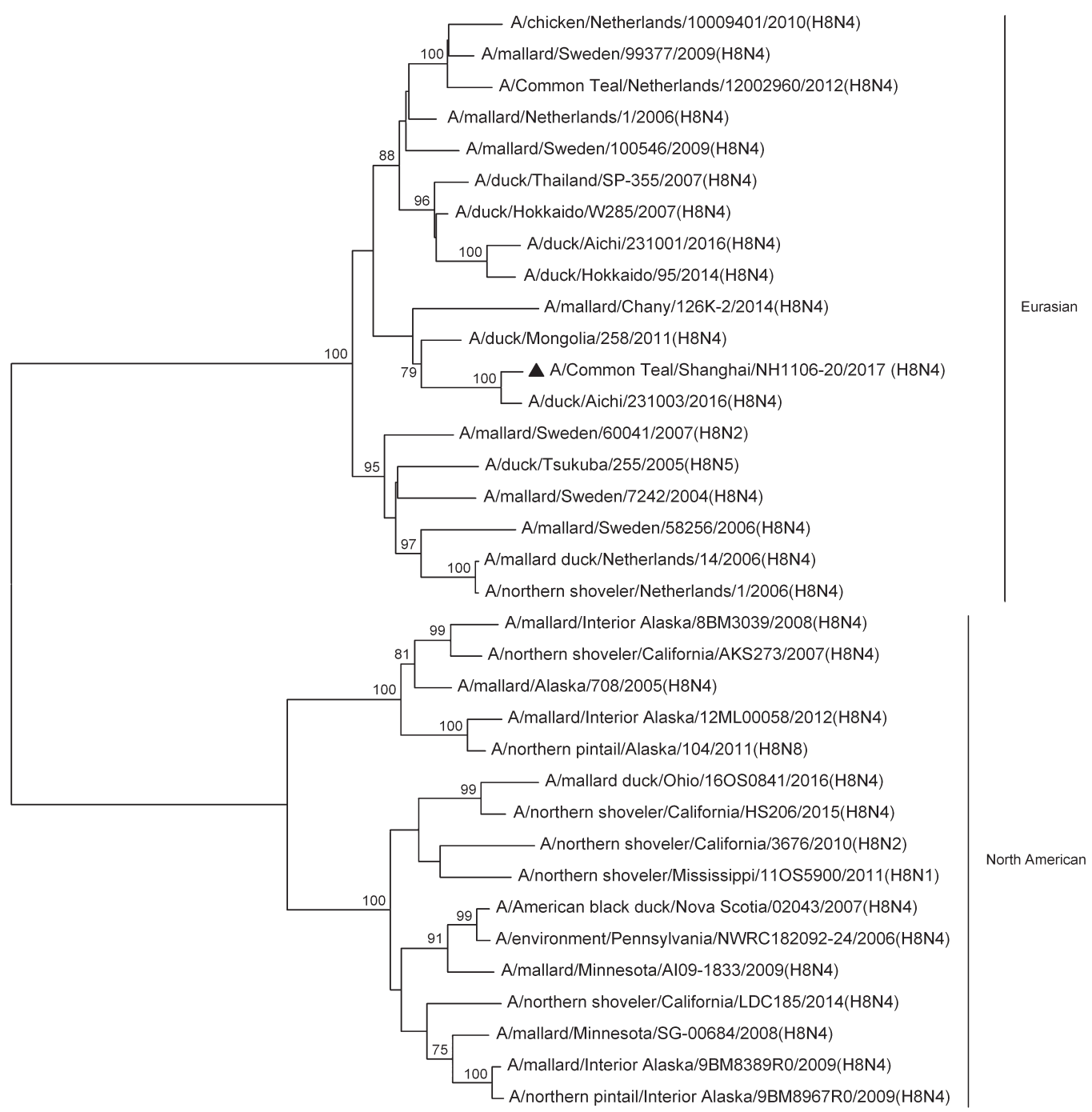

Fig. 1

Phylogenetic tree of the HA gene of the H8N4 virus isolated in Shanghai, China

The neighbor-joining tree was constructed using the Kimura 2-parameter model in MEGA software version 6.06 (http://www.megasoftware net/). Bootstrap values were calculated for 1000 replicates, and values less than $75 \%$ are not shown. Numbers indicate neighbor-joining bootstrap values. Virus characterized in this study is indicated by a filled triangle.

Table 1. Homology analyses of NH1106-20 (H8N4) with isolates in GISAID

\begin{tabular}{cllc}
\hline \multirow{2}{*}{ Gene } & $\begin{array}{l}\text { GISAID } \\
\text { Segment-ID }\end{array}$ & Virus & Homology \\
\hline PB2 & EPI683195 & A/duck/Wuhan/WHYF05/2014 (H9N2) & $99.46 \%$ \\
PB1 & EPI1159831 & A/duck/Dongting/D76-1/2016 (H5N7) & $99.69 \%$ \\
PA & EPI515113 & A/muscovy duck/Vietnam/LBM529/2013(H3N8) & $98.97 \%$ \\
HA & EPI866842 & A/duck/Aichi/231003/2016 (H8N4) & $99.19 \%$ \\
NP & EPI866843 & A/duck/Aichi/231008/2016 (H1N2) & $98.94 \%$ \\
NA & EPI866841 & A/duck/Aichi/231003/2016 (H8N4) & $99.64 \%$ \\
M & EPI704417 & A/duck/Mongolia/543/2015 (H4N6) & $99.89 \%$ \\
NS & EPI704570 & A/duck/Mongolia/520/2015(H1N1) & $99.65 \%$ \\
\hline
\end{tabular}




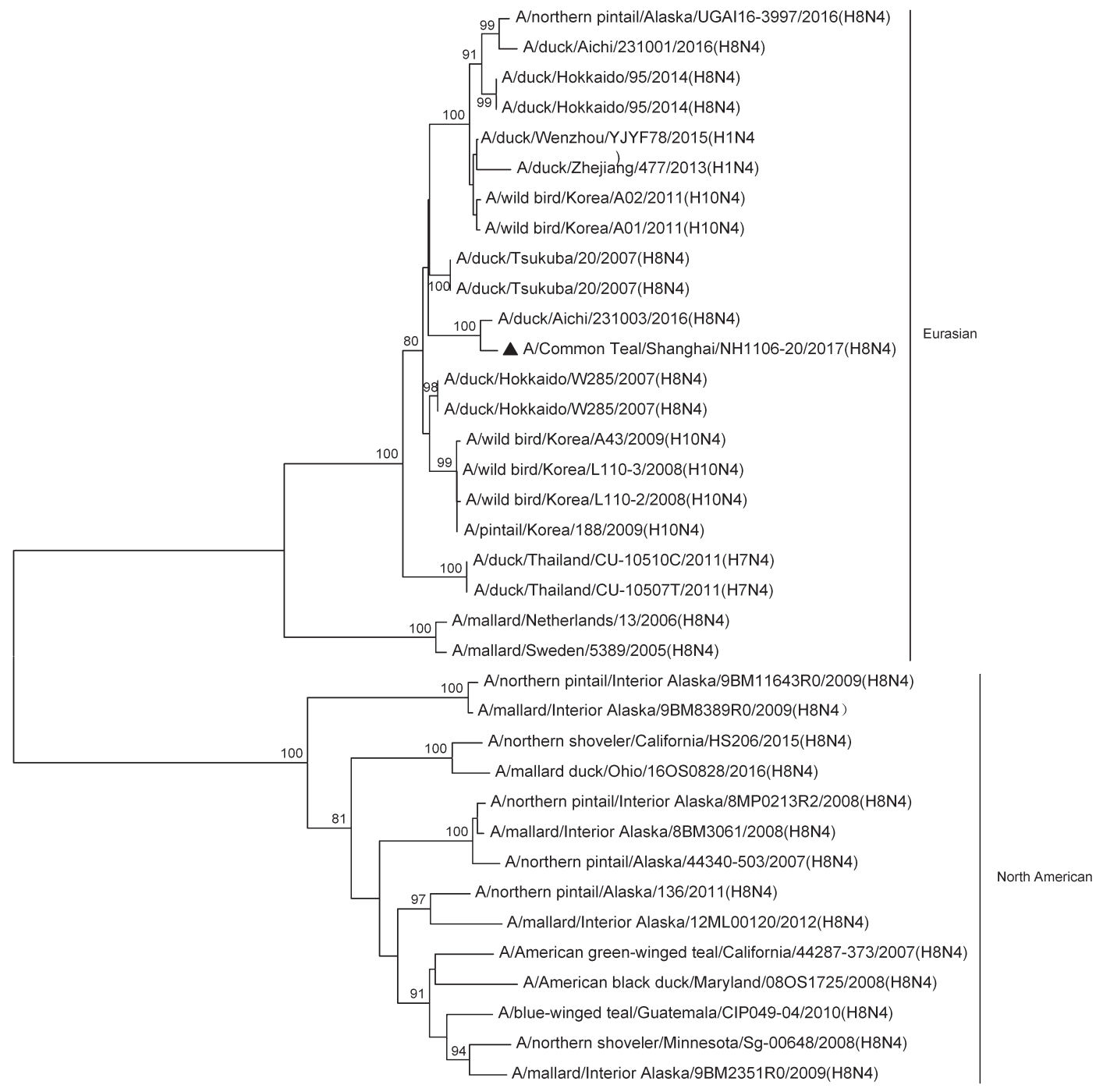

Fig. 2

Phylogenetic tree of the NA gene of the H8N4 virus isolated in Shanghai, China

The neighbor-joining tree was constructed using the Kimura 2-parameter model in MEGA software version 6.06 (http://www.megasoftware net/). Bootstrap values were calculated for 1000 replicates, and values less than $75 \%$ are not shown. Numbers indicate neighbor-joining bootstrap values. Virus characterized in this study is indicated by a filled triangle.

(Hoffmann et al., 2001). The PCR reaction contained $1 \mu$ of cDNA, $1 \mu \mathrm{l}$ of forward and reverse primers, $12.5 \mu \mathrm{l}$ of Taq HS Perfect Mix (Takara) and $10.5 \mu \mathrm{l}$ Rnase-free water, with a final volume of $25 \mu \mathrm{l}$. All sequences were confirmed using a BigDye termination kit (Applied Biosystems, Foster City, CA, USA) on an ABI 3730 sequence analyzer. The sequence data were aligned and analyzed using DNAMAN program (version 6.0). The phylogenetic trees were generated using the neighbor-joining algorithm and the 2-parameter model with bootstrap analysis (1000 replicates) in MEGA software (version 6.06). Sequences used for phylogenetic analysis were obtained from GenBank and the Global Initiative on Sharing Avian Influenza Data (GISAID) EpiFlu database.

Of the total 2394 samples, 160 influenza viruses were isolated and the prevalence was about $6.68 \%$. The most abundantly detected HA subtypes were H6 (37.8\%) and H4 (27.3\%), followed by H1 (12.1\%), H5 (10.6\%), H12 (4.5\%), H11 (3.0\%), H8 (1.5\%) and H3 (1.5\%). N2 (48.5\%) were the most freqently isolated NA subtpyes, followed by the N1 (15.2\%), N5 (6.1\%), N4 (1.5\%) and N6 (1.5\%). The $\mathrm{H} 8 \mathrm{~N} 4$ virus was isolated from Common Teal (Anas crecca) and named as A/Common Teal/Shanghai/NH1106-20/2017 
(H8N4, abbreviated as NH1106-20). The surveillance of AIVs in wild birds in Shanghai has been performed for more than ten years, but the wild bird-origin H8 subtype virus was firstly dected in this region, which further confirmed the H8 subtype viruses are rarely isolated from wild ducks (Olsen et al., 2006).

To clarify the genetic characteristics of the H8N4 virus, whole genome sequences were analysed and the sequences had been deposited in GenBank Acc. No. MH715345MH715352. As shown in Table 1, the HA and NA genes of NH1106-20 (H8N4) shared highest neucleotide identity (99.19\%-99.64\%) with the Japan duck-origin H8N4 virus collected in 2016 (A/duck/Aichi/231003/2016). As for the NP gene, NH1106-20 (H8N4) shared highest nucleotide identity (98.94\%) with the H1N2 duck-origin virus circulating in Japan, while the PA gene shared highest nucleotide identity (98.97\%) with the H3N8 wild bird-origin virus circulating in Vietnam. Regarding the other four internal genes, they shared highest nucleotide identity (99.46\%-99.89\%) with duck-origin H9N2, H5N7, H4N6 and H1N1 viruses circulating in Mongolia and in Central China. In the phylogenetic trees, the topology of the HA and NA genes of NH1106-20 (H8N4) are similar, all clustered together with the japanese isolates (A/duck/Aichi/231003/2016-H8N4) and belong to the Eurasian lineage (Figs. 1,2). Studies have shown that the $\mathrm{H} 8$ subtype has a complex genetic background and can easily recombine with other subtypes, including highly pathogenic influenza viruses (Sivay et al., 2014). Furthermore, the AIV hemagglutinin H8 also supports a highly pathogenic phenotype (Veits et al., 2012). The low pathogenic H8 subtype AIV may be transformed into highly pathogenic AIV by nucleotide mutations. Continued surveillance of circulating H8 subtype AIVs is needed for early warning the influenza outbreak.

Although the H8 subtype AIVs are more frequently detected in poultry than in wild birds (Verhagen et al., 2017), the influenza viruses are easily transmitted between wild birds and domestic waterfowl since they usually share the same waters. The wild birds can transmit the influenza virus to other domestic poultry through contact with them, then the virus can also spread and adapt in poultry and makes it possible to further recombine and mutate in live poultry markets and eventually infect humans (Peiris et al., 2007). Genetic analysis indicated that the HA and NA genes of the NH1106-20 (H8N4) have the highest similarity to the corresponding genes of $\mathrm{A} / \mathrm{duck} / \mathrm{Aichi} / 231003 / 2016$ (H8N4), therefore it can be speculated that the detected AIV may come from Japan duck, and were transmitted to Shanghai by the migration of wild birds.

In conclusion, we first identified a novel H8N4 subtype virus from wild birds in Shanghai, China. Phylogenetic analysis showed that the H8N4 strain resulted from reassortment of viruses of different subtypes circulating in Japan,
Vietam, Mongolia and in Central China. The study further enriched our understanding of the ecology of AIVs in Asia and stressed the importance of continuing surveillance of the AIVs in wild birds.

Acknowledgments. This work was funded by the Shanghai Committee of Science and Technology Grant (18DZ2293800), and the Shanghai Wildlife-borne Infectious Disease Monitoring Program. The capture, sampling and local release of wild birds have been approved, assisted and supervised by the Shanghai Wildlife Conservation and Management Office.

\section{References}

Butt K, Smith G, Chen H, Zhang L, Leung Y, Xu K, Lim W, Webster R, Yuen K, Peiris J (2005): Human infection with an avian H9N2 influenza A virus in Hong Kong in 2003. J. Clin. Microbiol. 43, 5760-5767. https://doi.org/10.1128/ ICM.43.11.5760-5767.2005

Fouchier R, Munster V, Wallensten A, Bestebroer T, Herfst S, Smith D, Rimmelzwaan G, Olsen B, Osterhaus A (2005): Characterization of a Novel Influenza A Virus Hemagglutinin Subtype (H16) Obtained from Black-Headed Gulls. J. Virol. 79, 2814-2822. https://doi.org/10.1128/ JVI.79.5.2814-2822.2005

Hill N, Takekawa J, Cardona C, Meixell B, Ackerman J, Runstadler J, Boyce W (2012): Cross-seasonal patterns of avian influenza virus in breeding and wintering migratory birds: a flyway perspective. Vector-Borne Zoonot. 12, 243-253. https://doi.org/10.1089/vbz.2010.0246

Hoffmann E, Stech J, Guan Y, Webster R, Perez D (2001): Universal primer set for the full-length amplification of all influenza A viruses. Arch. Virol. 146, 2275-2289. https://doi. org/10.1007/s007050170002

Olsen B, Munster V, Wallensten A, Waldenström J, Osterhaus A, Fouchier R (2006): Global Patterns of Influenza A Virus in Wild Birds. Pigs \& Poultry 312, 384-388. https://doi. org/10.1126/science. 1122438

Peiris J, Jong M, Guan Y (2007): Avian Influenza Virus (H5N1): A Threat to Human Health. Clin. Microbiol. Rev. 40, 243-267. https://doi.org/10.1128/CMR.00037-06

Sivay M, Sharshov K, Pantinjackwood M, Muzyka V, Shestopalov A (2014): Avian Influenza Virus with HemagglutininNeuraminidase Combination H8N8, Isolated in Russia. Genome Announc. 2(3), pii: e00545-14. https://doi. org/10.1128/genomeA.00545-14

Veits J, Weber S, Stech O, Breithaupt A, Gräber M, Gohrbandt S, Bogs J, Hundt J, Teifke J, Mettenleiter T (2012): Avian influenza virus hemagglutinins $\mathrm{H} 2, \mathrm{H} 4, \mathrm{H} 8$, and $\mathrm{H} 14$ support a highly pathogenic phenotype. Proc. Natl. Acad. Sci. USA 109, 2579-2584. https://doi.org/10.1073/ pnas. 1109397109

Verhagen J, Lexmond P, Vuong O, Schutten M, Guldemeester J, Osterhaus A, Elbers A, Slaterus R, Hornman M, Koch G (2017): Discordant detection of avian influenza virus 
subtypes in time and space between poultry and wild birds; Towards improvement of surveillance programs. PloS One 12, e173470. https://doi.org/10.1371/journal. pone. 0173470

Webster RG, Bean W, Gorman O, Chambers T, Kawaoka Y (1992): Evolution and ecology of type A influenza viruses. Curr. Top. Microbiol. 56, 359-375.
World Health Organization (WHO) (2009): CDC protocol of realtime RTPCR for swine influenza A (H1N1), http:// www.who.int/csr/resources/publications/swineflu/realtimeptpcr/en/.

Wu Y, Wu Y, Tefsen B, Shi Y, Gao G (2014): Bat-derived influenzalike viruses H17N10 and H18N11. Trends Microbiol. 22, 183-191. https://doi.org/10.1016/j.tim.2014.01.010 